\title{
Negociação coletiva de trabalho no Brasil após a reforma trabalhista de 2017
}

\section{Collective bargaining in Brazil after the 2017 labor reform}

\section{Otavio Pinto e Silva*}

\footnotetext{
* Professor Associado do Departamento de Direito do Trabalho e Seguridade Social da Faculdade de Direito da Universidade de São Paulo (USP).

凶otavio@siqueiracastro.com.br

http://orcid.org/0000-00031612-0747
}

RECIBIDO: [6.8.2018]

ACEPTADO: [3.9.2018]

\section{Resumen}

Este estudio examina las alteraciones producidas en la legislación brasileña en 2017 en materia de negociación colectiva laboral para demostrar que no hubo una reforma sindical sino, únicamente, modificaciones en el contenido de las normas colectivas de trabajo.

Palabras clave: sindicatos, negociación colectiva, Brasil.

\section{Resumo}

0 presente estudo examina as alterações efetuadas na legislação brasileira no ano de 2017 acerca da negociação coletiva de trabalho, para demonstrar que não houve uma reforma sindical, mas apenas modificações no conteúdo das normas coletivas de trabalho.

Palavras-chave: sindicato, negociação coletiva, Brasil.

\section{Abstract}

This study examines the changes introduced in the Brazilian labor legislation in 2017, in terms of collective bargaining, to demonstrate that there was no trade union reform but only changes in the content of collective labor standards.

Key words: trade unions, collective bargaining, Brazil 


\section{Introdução}

O ano de 2017 ficará marcado de forma indelével na história do Direito do Trabalho no Brasil, em razão das inúmeras alterações corridas na CLT, com a promulgação da Lei no $\mathbf{1 3 . 4 6 7 / 1 7 .}$

A legislação aprovada trouxe mudanças significativas no direito individual do trabalho, no direito coletivo do trabalho e no direito processual do trabalho, seguindo diretrizes gerais que, ao final, podem ser classificadas como «flexibilizadoras» do princípio protecionista.

O objetivo do presente artigo é examinar a nova regulamentação legal da negociação coletiva de trabalho no Brasil, de forma a avaliar o impacto dessas mudanças e demonstrar que elas não levaram ao aperfeiçoamento do sistema de organização sindical, eis que seguimos sem observar os parâmetros da liberdade sindical.

\section{A lei 13.467/17 e a prevalência do negociado sobre o legislado}

A chamada «reforma trabalhista» foi produzida em meio a uma grave crise política e econômica e se originou de um projeto de lei de iniciativa do Poder Executivo, encaminhado ao Congresso Nacional no final de 2016 pelo Presidente Michel Temer, após a aprovação do impeachment da Presidente Dilma Roussef.

Em 29 de outubro de 2015 a Fundação Ulisses Guimarães, braço do PMDB, havia divulgado o documento «Uma ponte para o futuro», ${ }^{1}$ onde proclamava que na área trabalhista seria necessário «permitir que as convenções coletivas prevaleçam sobre as normas legais, salvo quanto aos direitos básicos».

O projeto de lei encaminhado ao Congresso Nacional, assim, era bem restrito, limitando-se a tratar de poucos temas, como a terceirização, a negociação coletiva, a representação dos trabalhadores nos locais de trabalho.

A tramitação na Câmara dos Deputados resultou na aprovação de um substitutivo que ampliou significativamente os temas abordados, envolvendo mudanças no direito individual do trabalho, no direito coletivo do trabalho e também no direito processual do trabalho.

Encaminhado ao Senado Federal, o projeto foi apreciado por aquela que deveria cumprir o papel de uma casa revisora no sistema bicameral, mas que o aprovou sem fazer qualquer modificação no texto oriundo da Câmara.

1 http://pmdb.org.br/wp-content/uploads/2015/10/RELEASE-TEMER_A4-28.10.15-Online.pdf, consulta em $01 / 12 / 2017$ 
Dessa forma, em julho acabou sendo sancionada a Lei no $13.467 / 17$, em meio às turbulências políticas vividas pelo governo diante das graves denúncias de corrupção enfrentadas pelo Presidente Temer (em razão da acusação apresentada pelo Procurador Geral da República, Rodrigo Janot, que naquele momento ainda dependia de apreciação pelo plenário da Câmara dos Deputados).

A nova lei introduziu um $\S 3^{\circ}$ no art. 8을 da CLT, para prever que no exame de convenção coletiva ou acordo coletivo de trabalho, a Justiça do Trabalho analisará exclusivamente a conformidade dos elementos essenciais do negócio jurídico (respeitado o disposto no art. 104 da Lei nº 10.406, de 10 de janeiro de 2002, o Código Civil), e balizará sua atuação pelo princípio da intervenção mínima na autonomia da vontade coletiva.

Vale dizer, ao criar um «novo princípio», o legislador pareceu querer passar uma mensagem aos juízes do trabalho brasileiros: na análise das normas coletivas de trabalho, vocês devem apenas averiguar os elementos do negócio jurídico (agente capaz, forma prescrita ou não defesa em lei, objeto lícito). Esqueçam os debates doutrinários a respeito das teorias da acumulação ou do conglobamento!

No entanto, não me parece que essa criação legal de um princípio conseguirá atingir esse objetivo, uma vez que no exame do conteúdo das normas coletivas de trabalho, em confronto com a lei, o Judiciário sempre poderá concluir que determinado objeto é ilícito, anulando cláusula que tenha sido negociada pelas partes.

Em técnica legislativa que, decididamente, não é a mais adequada, o legislador inseriu ainda o art. 611-A da CLT (com o rol de temas a respeito dos quais a convenção coletiva e o acordo coletivo de trabalho têm prevalência sobre a lei) e o art. 611-B da CLT (prevendo que constituem objeto ilícito de convenção coletiva ou de acordo coletivo de trabalho, exclusivamente, a supressão ou a redução dos direitos que arrola).

Mas veja-se, por exemplo, as controvérsias que poderão surgir no tocante à norma do parágrafo único do artigo 611-B da CLT, quando prevê que as regras sobre duração do trabalho e intervalos não são consideradas como normas de saúde, higiene e segurança do trabalho para os fins do disposto neste artigo.

Ora, será que isso significaria, por exemplo, que um sindicato poderia negociar a supressão de pausas previstas na jornada de trabalho dos empregados em empresas de teleatendimento, previstas no Anexo II da NR-17 do Ministério do Trabalho?

Por outro lado, o $§ 2^{\circ}$ do artigo 611-A da CLT passou a prever que a inexistência de expressa indicação de contrapartidas recíprocas em convenção coletiva ou acordo coletivo de trabalho não ensejará sua nulidade, por não caracterizar um vício do negócio jurídico.

Será que então não ficarão mais sujeitas ao crivo judicial normas coletivas que apenas reduzam direitos e garantias anteriormente conquistados pela categoria profissional? 
Segundo a análise do DIEESE, a prevalência do negociado sobre o legislado, na ausência de outras condições necessárias à plena realização do potencial das negociações coletivas, trará elevados riscos para os trabalhadores. ${ }^{2}$

0 texto «Movimento sindical e negociação coletiva» (resultado de pesquisa CESIT/IE/UNICAMP - Centro de Estudo Sindicais e de Economia do Trabalho do Instituto de Economia da Unicamp, coordenada por Andréia Galvão) vai no mesmo sentido: em suas conclusões, assevera que ao ampliar as formas de contratação atípicas e as possibilidades de negociação de direitos, a reforma tende a promover o aumento do número de trabalhadores precários, a reduzir a base de representação sindical e a ampliar ainda mais a fragmentação sindical. A mudança no financiamento não pode ser feita de forma isolada e de cima para baixo, devendo ser inserida em um debate mais geral acerca da reforma da estrutura sindical do país. ${ }^{3}$

Já a CNI faz uma análise mais otimista, por meio do texto «Novos Desafios, Muitas Possibilidades: legislação e prática da negociação coletiva - Lei 13.467 de 2017».. A entidade empresarial sustenta que a negociação coletiva enfrentou dificuldades no Brasil, em razão da

desconfiança de parcela de importantes instituições do mundo do trabalho, como o Judiciário Trabalhista e o Ministério Público do Trabalho - MPT, que muitas vezes entendiam necessário considerar inválidas cláusulas de negociações coletivas livremente negociadas, por vezes com apoio de súmulas de jurisprudência do TST, entre as quais: redução do intervalo intrajornada (Súmula 437, II), elastecimento dos minutos que antecedem e sucedem a jornada de trabalho (Súmula 449), compensação de jornada em atividade insalubre (Súmula 85, VI), incidência do adicional de periculosidade de eletricitários sobre o salário básico (Súmula 191), fixação do adicional de periculosidade proporcionalmente ao tempo de exposição à condição perigosa (Súmula 364, II).Tal cenário motivou a aprovação da Lei $13.467 / 2017$, que tem como um de seus cernes principais o fortalecimento e reconhecimento da negociação coletiva.

A função de negociação deve ser plenamente assegurada, pois é a partir dela que os sindicatos exercem o poder de criação de normas jurídicas trabalhistas que devem reger as relações individuais de trabalho (convenções e acordos coletivos de trabalho); mas é preciso advertir que a mera garantia formal da existência de sindicatos é insufi-

https://www.dieese.org.br/notatecnica/2017/notaTec178reformaTrabalhista.html, consulta em $03 / 12 / 2017$.

3 http://www.cesit.net.br/wp-content/uploads/2017/11/Texto-de-discussão-5-Negociacao-coletiva-esindicalismo-1.pdf, consulta em 09/12/2017.

4 http://www.portaldaindustria.com.br/relacoesdotrabalho/media/publicacao/chamadas/Novos_ Desafios_web.pdf consulta em 01/03/2018. 
ciente. Na verdade, é necessário averiguar o modo como o sindicato é concebido e a maneira como se relaciona com seus representados, com outras entidades e com o próprio Estado.

A reforma trabalhista prevê ainda que as condições estabelecidas em acordo coletivo de trabalho sempre prevalecerão sobre as estipuladas em convenção coletiva de trabalho (artigo 620 da CLT), parecendo com isso buscar privilegiar a realização de negociação em nível de empresa.

Outro ponto que gerou muita polêmica foi a vedação da ultratividade da norma coletiva de trabalho (artigo 614, § 3ํㅡㄹ da CLT): a medida, apontada como uma reação do Legislativo contra a edição da Súmula 277 pelo TST, poderá levar o empregador a não se interessar pela negociação coletiva.

Nesse sentido, vale citar a crítica de Mauricio Godinho Delgado e Gabriela Neves Delgado:

Prestigiar um critério interpretativo segundo o qual, em um único dia, dezenas de cláusulas e direitos inerentes a certo ACT ou CCT desapareceriam da regência normativa das categorias e dos contratos de trabalho, abrindo-se dramático limbo jurídico nesse segmento socioeconômico e profissional, consiste em desequilibrar, demasiadamente, de maneira manifestamente desproporcional, a balança do poder ente o sindicato de trabalhadores e a respectiva empresa empregadora ou a correspondente categoria econômica (DELGADO, 2017).

Enfim, somente se pode cogitar de efetiva garantia da autonomia privada coletiva quando o ordenamento jurídico não apenas assegura o «reconhecimento» de acordos e convenções coletivas de trabalho (artigo 7ํㅜ, inciso XXVI, da Constituição Brasileira), mas vai mais além, promovendo e incentivando a função negocial.

É o que prega a Organização Internacional do Trabalho: a Convenção 98 da OIT aponta a importância da função negocial do sindicato, ao assinalar a necessidade da adoção de medidas adequadas para estimular trabalhadores e empregadores ao pleno desenvolvimento dos procedimentos de negociação.

Numa perspectiva de valorização dos direitos humanos ligados ao trabalho é que a OIT vem pautando sua atuação desde 1998, quando aprovou a Declaração relativa aos Princípios e Direitos Fundamentais no Trabalho, que acentua a necessidade de se assegurar a liberdade de associação e liberdade sindical e reconhecimento efetivo do direito de negociação coletiva, em conformidade com as Convenções 87 e 98.

No entanto, a Convenção 87 da OIT ainda não foi ratificada pelo Brasil, o que é indispensável para que se possa falar em efetiva valorização da autonomia privada coletiva, na busca de um modelo que vise assegurar aos particulares, na prática, os mecanismos necessários para a autorregulamentação de condições de trabalho. 
Infelizmente, nada disso foi mexido na chamada «reforma trabalhista», o que nos leva a um certo descrédito quanto ao efetivo êxito da nova negociação coletiva que se apregoa ter sido implantada no Brasil.

Aliás, estudos efetuados na vigência da nova legislação pela FIPE - Fundação Instituto de Pesquisas Econômicas, divulgados em julho/2018, indicam uma queda de $39,6 \%$ no número de acordos e convenções coletivas de trabalho formalizados no Ministério do Trabalho no primeiro semestre de 2018, em comparação com o mesmo período de $2017 .^{5}$

\section{A reforma sindical que não houve}

Estudo publicado pelo Instituto de Pesquisa Econômica Aplicada (IPEA) ${ }^{6}$, da lavra de André Gambier Campos, aponta a existência de 16.491 organizações sindicais de representação de interesses econômicos e profissionais no Brasil, registradas no Ministério do Trabalho até o final do ano de 2016. Seguindo os níveis hierárquicos da estrutura oficial, há 15.892 sindicatos, 549 federações, 43 confederações e 7 centrais sindicais, totalizando 16.491 organizações que representam empregadores (5.251) e trabalhadores (11.240).

As transformações no direito trabalho brasileiro precisariam ter começado pela organização sindical e representação dos trabalhadores no local de trabalho, com a aplicação prática do princípio da livre formação de sindicatos: ou seja, deveria ter sido garantido aos grupos de trabalhadores ou de empresários o direito de criar livremente suas entidades sindicais, sem a sujeição a atos de ingerência do poder público.

Enfim, para que o objetivo de fortalecimento da negociação coletiva seja efetivamente alcançado, diversas outras medidas reformadoras ainda precisam ser aprovadas, muitas delas implicando a necessidade de emenda constitucional. Senão, vejamos.

\section{Supressão da unicidade sindical}

A primeira das medidas reformadoras é a supressão da regra da unicidade sindical, prevista no artigo 8o , inciso II, da Constituição Federal.

Os parâmetros para a organização sindical devem ser os estabelecidos pela Convenção 87 da OIT, que consagra os princípios da liberdade e autonomia sindical.

Cabe aos interessados - trabalhadores e empregadores - definir quantas e quais entidades representarão seus interesses.

5 http://www.fipe.org.br/pt-br/indices/salariometro/, consulta em 01/08/2018.

6 http://www.ipea.gov.br/portal/images/stories/PDFs/TDs/td_2262.pdf, consulta em 02/12/2017. 
A unidade do movimento sindical não deve ser imposta mediante intervenção legislativa estatal, pois tal intervenção contraria o princípio de liberdade sindical previsto no artigo $2^{\circ}$ da referida convenção internacional.

\section{Eliminação das categorias como formas obrigatórias de organização sindical}

Se a regra deve ser a liberdade sindical, não cabe ao Estado definir os contornos das entidades representativas de trabalhadores e empresários.

Sendo assim, uma segunda medida indispensável é a supressão tanto na Constituição (artigo 8º, inciso II) quanto na lei (parágrafos do artigo 511 da CLT) das referências aos conceitos de categorias econômica, profissional e diferenciada como formas obrigatórias de organização em entidades sindicais.

Não deve o Estado estabelecer a forma de organização dos sindicatos, impondo a existência das categorias; ao contrário, a possibilidade de escolha precisa ser atribuída aos próprios grupos.

Pode até ser que a similitude das condições de vida e de trabalho decorrente das atividades desenvolvidas justifique a continuidade da existência de sindicatos tradicionais; mas cabe aos trabalhadores (e somente a eles) decidir se devem se organizar de tal forma.

Por outro lado, aos empresários também deve ser deixada a opção da forma mais conveniente de organização sindical, em vista da solidariedade de interesses econômicos que possam ter, diante das atividades que desempenham.

A enorme proliferação de sindicatos que se deu no Brasil a partir da Constituição de 1988 deixa claro que o critério da unicidade sindical por categoria não garante a união dos trabalhadores, na medida em que foram inúmeras as categorias profissionais surgidas sem um mínimo de representatividade (gerando disputas judiciais pelo direito de representação que demonstram não ter sido alcançada a unidade de ação que decorreria do sistema previsto no artigo 8o da Constituição).

\section{Revogação da base territorial mínima municipal}

A terceira medida de garantia da liberdade e autonomia sindical é a revogação da regra constitucional (também contida no inciso II do artigo $8^{\circ}$ ) que prevê a área do Município como limite mínimo da base territorial de atuação dos sindicatos.

Deve ser aberta a possibilidade de criação de sindicatos por empresas ou por região geográfica, em conformidade com a similitude das condições de trabalho nas 
empresas envolvidas e de acordo com as conveniências e circunstâncias ditadas unicamente pelos interesses dos trabalhadores e empresários.

Bastam os exemplos das grandes metrópoles e da pluralidade de atividades econômicas desenvolvidas em seu território para justificar a possibilidade de criação de um sindicato que busque atuar em apenas uma parte do Município.

Ou ainda, não deve ser desprezada a possibilidade de criação de sindicatos por empresas, segundo a avaliação de conveniência de tal medida, o que deve ser objeto de deliberação exclusiva dos interessados.

\section{Novas formas de custeio da atividade sindical com o fim da contribuição sindical compulsória}

A reforma trabalhista trouxe o fim da contribuição sindical compulsória, que efetivamente não se justifica em um sistema de liberdade sindical. Agora, a legislação exige a prévia e expressa autorização dos membros da categoria para que o sindicato possa exigir o pagamento de uma contribuição.

Em 29.06.2018, na apreciação da Ação Direta de Inconstitucionalidade 5794, o Supremo Tribunal Federal (STF) decidiu, por maioria e nos termos do voto do Ministro Luiz Fux, julgar improcedentes os pedidos formulados e declarar a constitucionalidade da parte da legislação que aprovou a reforma trabalhista e extinguiu a obrigatoriedade da contribuição sindical.

Os trabalhadores e os empresários devem ter o direito de se filiar à organização sindical de sua escolha, com a única condição de conformarem-se aos seus estatutos.

0 artigo $2^{\circ}$ da Convenção 87 consagra o direito do indivíduo aderir ou não à entidade sindical, isto é, não impõe um dever de sindicalização; de tal forma, a obrigação de pagar uma contribuição ao sindicato pressupõe o ato voluntário de filiação.

A liberdade sindical é incompatível com a imposição (por via legal ou constitucional) do pagamento da contribuição sindical obrigatória: se a sindicalização é um direito, a contribuição não pode ser uma obrigação.

É de se lamentar a omissão do Congresso Nacional em debater e aprovar a norma legal que viria substituir a contribuição sindical compulsória pela chamada contribuição negocial, vinculada ao resultado da negociação coletiva e condicionada à aprovação de assembleia dos trabalhadores representados.

Essa mudança chegou a ser prometida no artigo 7ํ da Lei n॰11.648/2008 (que regulamentou as Centrais Sindicais), mas ao que parece que ficou relegada a um momento futuro e incerto, pois nada se cogitou a respeito por ocasião da reforma trabalhista.

Modificar o custeio compulsório dos sindicatos e a exclusividade de sua organização em um território local são medidas relevantes, pois a combinação de ambos os 
mecanismos é um dos motivos por trás do aumento no número de sindicatos no Brasil, ano após ano, devido a disputas envolvendo os recursos financeiros da contribuição obrigatória (Campos, 2017).

\section{Estímulo à representação e participação dos trabalhadores no local de trabalho}

A quinta transformação necessária consiste na criação de novas formas de representação e participação dos trabalhadores no local de trabalho.

É preciso ampliar os canais institucionais de atuação dos trabalhadores, incrementando a sua representação e participação no quotidiano empresarial, de maneira a tornar mais frequentes as negociações nos próprios locais de trabalho e a democratizar a gestão.

A representação é uma forma de atuação dos trabalhadores no local de trabalho para a defesa e promoção de seus interesses individuais e coletivos; já a participação constitui mecanismos por meio dos quais os trabalhadores participam da gestão, dos lucros ou do capital da empresa (Silva, 1998).

Existem dois dispositivos constitucionais nesse sentido que devem ser lembrados: o artigo 11 (que assegura, nas empresas com mais de duzentos empregados, a eleição de um representante destes com a finalidade exclusiva de promover-lhes o entendimento direto com os empregadores) e o inciso XI do artigo 7ํㅜ (que prevê a participação dos trabalhadores, em caráter excepcional, na gestão da empresa).

A Lei no 13.467/17 regulamentou o artigo 11 da Constituição para estabelecer uma nova forma de representação dos trabalhadores, a ser adotada nas empresas com mais de duzentos empregados. Agora passa a ser prevista a eleição de uma comissão com a finalidade de promover o entendimento direto com o empregador; mas se serão mesmo instaladas, não se sabe. E a sua efetiva representatividade ainda é algo incerto, pois não há uma clara definição de diretrizes para sua atuação.

\section{Proteção contra os atos antissindicais}

Uma sexta providência imprescindível é a inclusão no ordenamento jurídico de mecanismos efetivos de proteção contra os atos antissindicais, medida que visa dar legitimidade ao processo de negociação coletiva, estabelecendo garantias para o livre exercício da atividade dos sindicatos.

São classificados como antissindicais quaisquer atos que venham a prejudicar indevidamente o titular de direitos sindicais, quando em exercício de atividade sindical. 
O sujeito prejudicado tanto pode ser um indivíduo quanto o próprio sindicato: como exemplos, podem ser citados atos como a despedida injusta de dirigente sindical, a proibição de distribuição de material informativo do sindicato na porta da empresa, ou ameaças do empregador que visem desencorajar os seus empregados de se filiarem ao sindicato.

Quanto aos agentes, capazes de praticarem tais atos, podem ser arrolados os empregadores e seus prepostos, as organizações de empregadores e até mesmo o Estado (este, tanto no seu papel de empregador quanto no de autoridade administrativa).

A oIT expressa a sua preocupação quanto à necessidade de previsão de mecanismos de proteção contra os atos de «discriminação» e de «ingerência».

O conceito de «atos de discriminação» está previsto no artigo $1^{\text {o da Convenção no }}$ 98 da OIT, de 1949. Os trabalhadores gozarão de adequada proteção contra atos de discriminação com relação a seu emprego. Essa proteção aplicar-se-á especialmente a atos que visem: a) sujeitar o emprego de um trabalhador à condição de que não se filie a um sindicato ou deixe de ser membro de um sindicato; b) causar a demissão de um trabalhador ou prejudicá-lo de outra maneira por sua filiação a um sindicato ou por sua participação em atividades sindicais fora das horas de trabalho ou, com o consentimento do empregador, durante o horário de trabalho.

Já a noção de «atos de ingerência» está prevista no artigo 2º da Convenção no 98 da OIT. As organizações dos trabalhadores e dos empregadores gozarão de adequada proteção contra atos de ingerência de umas nas outras, ou por agentes ou membros de umas nas outras, na sua constituição, funcionamento e administração. Serão considerados atos de ingerência, nos termos deste artigo, promover a constituição de organizações de trabalhadores dominadas por organizações de empregadores ou manter organizações de trabalhadores com recursos financeiros ou de outra espécie, com o objetivo de sujeitar essas organizações ao controle de empregadores ou de organizações de empregadores.

A experiência da Comissão de Peritos da oIT revela que a existência de normas legislativas fundamentais que proíbam atos antissindicais é insuficiente, se estas não vem acompanhadas de procedimentos eficazes que garantam sua aplicação na prática. Alguns requisitos são apontados para a eficácia dos mecanismos de proteção:

1. a possibilidade de suspensão liminar do ato antissindical, para evitar que os seus efeitos se consolidem antes de uma decisão definitiva;

2. uma diferenciação na distribuição do ônus da prova, pois pode ser muito difícil para o trabalhador ou para a sua entidade provar que determinado ato patronal está sendo praticado com fim ilícito: assim, por exemplo, surge a necessidade de o empregador demonstrar que uma despedida que está sendo questionada tenha um determinado fundamento; 
3. a celeridade do processo, uma vez que a lentidão para a solução de pendência acerca de um ato antissindical gera dois efeitos perversos: de um lado, se o ato não é suspenso provisoriamente, produz seus efeitos ilícitos durante todo esse tempo, e por outro lado, nesse mesmo período é possível que a situação violadora se consolide, tornando impraticável uma solução reparatória tardia.

\section{Enfrentamento da crise de representatividade sindical}

Constata-se que existem várias premissas indispensáveis para que se possa falar em um sistema de organização sindical fundamentado no critério de liberdade.

Essas premissas devem fazer parte de uma reforma do nosso modelo, pois somente com a tutela da liberdade sindical é que o Estado poderá garantir o desenvolvimento de negociações coletivas autênticas.

Vale dizer, a autonomia privada coletiva está vinculada à efetividade da representação sindical: as ambíguas instituições legais brasileiras condicionam uma estrutura legal burocratizada e desvinculada das bases, fatores esses que impedem o nosso movimento sindical de demonstrar sua capacidade de viver democraticamente e atingir sua plena maturidade (Massoni, 2007).

Ao se discutir o papel da negociação coletiva na regulação do trabalho, portanto, é indispensável a revisão do modelo de organização sindical (Campos, 2017).

Em síntese, o que se pode afirmar é que o grande dilema do sindicalismo no século XXI não é outro senão o de obter efetiva representatividade, pois esta é a única forma de sobreviver ao novo sistema de relações de trabalho que vem sendo desenhado.

\section{Garantia do direito de greve}

Não há negociação coletiva de trabalho autêntica sem que o Estado assegure a efetiva garantia do direito de greve. A diretriz prevista no artigo 9o da Constituição brasileira precisa ser observada na prática: cabe aos trabalhadores decidir pela oportunidade do exercício do direito de greve e sobre os interesses que devam por meio dele defender.

A nossa lei de greve ainda necessita ser aperfeiçoada, incluída aí a regulamentação do exercício do direito pelos servidores públicos. 


\section{Conclusão}

A modernização do direito do trabalho no Brasil necessariamente passa pelo enfrentamento da questão da reforma sindical, que infelizmente ficou à margem da Lei no $13.467 / 17$.

Um modelo de relações de trabalho que realmente valorize a autonomia privada coletiva depende da efetiva garantia da liberdade de organização sindical e de exercício das funções negociais.

O Congresso Nacional ainda deve ao povo brasileiro a indispensável reforma sindical, como verdadeira garantia de acesso ao trabalho decente pela via da negociação coletiva.

\section{Referências}

CAmPos, André Gambier. «Sindicatos no Brasil: o que esperar no futuro próximo?» In: http://www.ipea.gov.br/portal/images/stories/PDFs/TDs/td_2262.pdf. Rio de Janeiro: IPEA, 2016.

Delgado, Mauricio Godinho; Delgado, Gabriela Neves. A Reforma Trabalhista no Brasil. São Paulo: LTr, 2017.

MASSONI, Túlio de Oliveira. Representatividade sindical. São Paulo: Editora LTr, 2007

Silva, Otavio Pinto e. A contratação coletiva como fonte do direito do trabalho. São Paulo: LTr, 1998.

SILVA, Otavio Pinto e. Subordinação, autonomia e parassubordinação nas relações de trabalho. São Paulo: LTr, 2004.

SILVA, Walküre Lopes Ribeiro da. Representação e participação dos trabalhadores na gestão da empresa. São Paulo: LTr, 1998. 